\title{
Exploring the Teaching Mode of "Sub-classroom" with Students as the Center
}

\author{
Xiuying Yang ${ }^{1}$, Mingyu Zhao ${ }^{1}$, Rui Zhang ${ }^{1}$ \\ ${ }^{1}$ Shenyang Institute of Technology, Fushun, Liaoning, 110136
}

Keywords: Dividing Classroom, Student-centered, Teaching Mode

\begin{abstract}
The modern teaching concept requires that teaching activities not only increase the amount of knowledge of students, but also cultivate their ability to think and learn independently. The sub-classroom teaching mode focuses on the generation of knowledge and the self-construction of knowledge, focusing on the constructive and generative nature of knowledge learning. In the teaching activities, the roles of teachers and students are repositioned from the discussion stage, the teaching stage, and the internalization process. The author believes that to improve the teaching effectiveness of the sub-classroom, in practice, it is necessary to use the strength of teachers to establish a psychologically compatible class atmosphere, change the traditional concept of students, and enhance the systematic nature of the content of the lectures.
\end{abstract}

\section{Introduction}

The essence of the dichotomy is to strengthen the training of critical thinking skills in order to achieve the goal of true education. The purpose of education is to inspire wisdom and to explore the brain power and initiative of the educated. Education is a cloud that pushes another cloud. It depends on the role and strength of people to promote, and "flip classroom" can not be done, at least not good, flipping the video of the classroom can easily give students basic knowledge and information, but after-school learning lacks interaction and enlightenment, It is completed by the students themselves. This kind of flipping classroom puts high demands on the individual consciousness and quality of the students. It is suitable for individual students with strong autonomy, but it is not suitable for all students. It is much more operability than the subclass.

\section{Split classroom teaching mode}

The dichotomous classroom teaching mode is a new type of classroom teaching model that emphasizes the teacher-student's main body teaching mode, which is aimed at the teacher-centered traditional classroom teaching mode, in order to effectively improve the teacher-student interaction in the university classroom life. The shortcomings of the separation of teachers and students make teaching and learning truly a two-way interactive process. The current university classroom is a teaching model that emphasizes education and teaching. "A subconscious premise of adopting this kind of classroom teaching rules is that students are ignorant of what they have learned, and they need to rely on the teacher's teaching and instilling to provide them with a complete knowledge system." So, the teacher The identity of "the occupants and spokespersons of knowledge and skills" became the protagonist in the classroom, and the students were only the actors. Under this circumstance, there is no common foundation between teachers and students. The exchange based on the search for truth cannot be deepened, which leads to the separation of the process of teacher teaching from the process of student learning: teachers rack their brains to prepare lessons, as much as possible Full, in-depth lectures, and try to incorporate the most cutting-edge research results and disciplinary dynamics into the teaching content, presented to the students; and students do not have to worry, brains, only bring a pair of ears to the classroom to listen, learning becomes passive Simple, mechanical. As for the course assessment, you only need to make a copy of the "School" notes before the exam, and you can pass the assault. In the long run, the teaching relationship between teachers and students is alienated and tense. Teachers define the relationship between teachers and students simply as the relationship between "servicer" and "customer". Students regard 
themselves as teachers' "God" and "clothing parents". This is not only inconsistent with the traditional culture of our country, but also does not meet the practical requirements of establishing a harmonious teacher-student relationship in higher education institutions, and it has a certain degree of influence on the enthusiasm of teachers to teach and educate people.

The starting point and the end point of education are the growth and development of students. Compared with primary and middle school students, the learning needs, learning enthusiasm and learning initiative of college students should be far superior to those of primary and middle school students. On the contrary, compared with the learning motivation of primary and middle school students who are encouraged by the promotion of college education, college students have lost the motivation to learn because they lost the goal of "advancement". The university has also become the pressure for many students to release basic education. A place to recuperate. The teaching mode dominated by university classroom teachers, regardless of the teacher, only pays attention to the quality of the teacher's teaching but does not pay attention to the quality of the student's learning. It makes the classroom teaching of the university seem to be a unilateral activity of the teacher. Only the teacher prepares the lesson without the student. In preparation, only the voice of the teacher is heard in the classroom. The lack of student participation, interaction and response has contributed to the self-sluggishness and laziness of the college students. This leads to the strange phenomenon of the university campus: the teachers are too tired to die. I have to die; the teacher complains that the students are not passionate about learning, and the students complain that the teacher is not interested in class, causing the teacher-student relationship to be alienated or nervous. In order to improve the quality of university classroom teaching, it is necessary to change the teaching mode of the former teacher's one-man show, so that students become the real protagonists of classroom teaching activities. The bi-class classroom teaching mode is a "student-centered" model, with a new teaching mode in which students and students and students learn interactively as the main form of classroom teaching activities. This teaching mode enables teachers and students to rely on each other in the teaching time and space of the classroom, fully enjoy their respective teaching and learning rights, and position and timely change the roles of teachers and students in various dynamic links of the teaching process, so that students can truly Participate in the classroom life, promote the development of their learning ability and innovative thinking, and make the classroom life of the university glow in the flexible and efficient classroom interaction between teachers and students.

\section{The implementation of the three-division classroom teaching mode}

The teaching method of the dichotomy class is to organize the classroom life according to the three links of lecture, internalization and discussion. The course teaching can be divided into three stages of learning process: the first stage is the teaching stage, in the first class, the teacher lectures, the teacher mainly introduces the basic framework, concepts and theoretical logic of the chapter. Focus on teaching key points and difficulties, but not exhausting all the contents of the textbooks, and reserve space for students to learn and think after class. The second stage is the after-school learning stage, which is mainly completed by the students after class. That is, about one week after the last class is the internalization and absorption stage of the students. According to the differences in personal thinking characteristics and learning ability, the students carefully check the literature and carefully Analytical research, etc., understand the content of the digestive classroom, and expand and extend, laying the foundation for the subsequent classroom discussion. The third stage is the class discussion stage. In the second class, the students discuss the content of the last class in the class, and the representatives of the teams send out the questions and learning experiences in the course. Classmates and classroom teachers carry out in-depth interactive exchanges to explain doubts. The dichotomous classroom teaching mode is a three-step process designed according to the cognitive psychology rules acquired by individual knowledge. The previous link plays a foundation role for the next link. The effect of the previous link determines whether the next link can be effectively carried out. Therefore, each link puts forward corresponding teaching ability requirements for the specific roles of teachers and students as the main body of the teaching in this 
link. Only in this way can the effective connection and integration of the three teaching links be realized.

The three teaching links of the classroom teaching model are based on the characteristics of the university curriculum and the differences between the student groups and the actual situation of the individual. The lectures given by the teachers are based on the characteristics of the university curriculum. "The distinctive feature of higher education is its strong professionalism. Professional education means that students need to gain specific expertise in the university." Therefore, the content of the university curriculum is highly specialized and requires some expertise. As a basis, students, especially those in the lower grades, rely on the accumulation of existing knowledge and are not easy to understand. They need teachers to give certain professional explanations and provide guidance for students to learn independently, and to provide guidance on theories, methods and ways of thinking. In order to give students a certain amount of time to understand, digest and learn the content in depth, it provides an opportunity for each student to participate in the classroom discussion effectively and effectively. However, this preparation time should not be too long, so that the new course learning content will dilute the previous learning content and affect the effect of the course discussion. The class discussion session also consists of two parts. The first part is the internal discussion of the group. The group members exchange their own learning experiences and opinions and form a group discussion. The latter part is to conduct the discussion of the results of each group in the whole class. Communication, the problem of commonality can be solved through communication and discussion with the teacher. The teaching method of the sub-classroom is to complete the teaching objectives and tasks of the course through the three teachings that are connected to each other. Of course, the effectiveness of the teaching model of the sub-class will ultimately depend on the rational positioning and transformation of the teacher and student roles in the teaching process.

\section{Student role in 4-point classroom teaching mode}

Teachers and students are interactive subjects in teaching activities, and the role transformation of teachers always corresponds to the role transformation of students. In the different teaching and learning sections of the classroom teaching model, the role of the students is also constantly changing in the interaction with the teacher's role. The learning tasks undertaken in different classroom roles are different, and the learning requirements for students are naturally different. Therefore, clarifying the role of students in the various aspects of the classroom teaching model helps to clarify the students' learning tasks, enhance the relevance of teachers' teaching and guidance, and enhance the practical effect of classroom teaching.

The halve classroom teaching mode is a teaching mode that highlights the subjective initiative learning. In the traditional teaching mode, students only need to access a large amount of information in a short period of time, and master and memorize a large number of concepts, principles, formulas and causal relationships. In the classroom teaching mode, the teaching is only the introduction of teaching activities. Students only need to familiarize and understand the topics taught by the teachers, form a problem domain or outline outline for the propositions related to the topic, form the basic framework structure of the problem, grasp and clarify the key points and difficulties in the unit knowledge learning, and clarify I need to solve problems on my own under the class; I don't need too many memories and memorization, and I don't need to spend too much brain power. I just understand the questions and arrangements of the teachers by listening and taking notes. You can do your homework. It can be said that in the teaching process, the students are mainly as the initial recipients of knowledge, absorb the basic information of the course content provided by the teachers, and provide basic support and guidance for self-learning and in-depth study after class and the next class discussion. In this sense, the degree of acceptance of knowledge by the students in the lectures is crucial, and directly determines the quality and effect of the completion of the latter two teaching tasks.

For students, classroom participation helps students to experience knowledge and become an integral part of their knowledge system, while classroom discussion is the most effective way to 
participate in class. There are significant individual differences in the learning process. In order to achieve the integration and complementation of differences among students, the constructivist teaching theory advocates the use of group-based learning methods. It is considered that students can more easily discover and understand complex concepts by discussing each other's problems, emphasizing the demonstration effect of group members' correct thinking. It makes it easier for students to expose and challenge each other's misconceptions and form a questioning quality of thinking. Based on this theoretical logic, the classroom teaching mode is the most important part of classroom teaching. This link is not only for the inspection and feedback of the above two learning experiences, but also an important way for students to learn interactively between teachers and students. Different from the previous discussion class for a broader discussion mode for a topic in the entire course content, the discussion topic in the sub-class teaching mode is fixed and is a specialized discussion on the content of the last lesson. As members of different groups, each student should actively communicate and communicate with the group members on their own learning experiences, experiences and questions, confusions, etc., and learn from each other in the exchanges, reach a consensus, form a group discussion. opinion. Then, the second level of discussion and communication at the whole class level will be carried out on the opinions formed by each group discussion, so as to realize the teaching and learning and the common progress between the teachers and students in the class sense.

\section{Conclusion}

Creating a new type of classroom teaching mode is the inevitable pursuit of university classroom teaching reform, and it is also the only way to improve the quality of college personnel training. The dichotomous classroom teaching mode is only a preliminary reform exploration and attempt in this aspect. Whether it can achieve the expected teaching effect, it is not only necessary to continuously research and improve this model, but also the support and cooperation of the entire teaching management system. In this way, the goal of improving the quality of university classroom teaching can be achieved.

\section{References}

[1] Liu Tiefang. On the communication and its obstruction in education [J]. Chinese Journal of Education, 1996(3): 16-20.

[2] Sun Jiaoyan. Higher education quality concept based on ISO9000 series standards [J]. Journal of Dalian Maritime University: Social Science Edition, 2005 (3): 87-89.

[3] Yang Wei. Towards professional growth of college students entrepreneurship education [J]. Liaoning Normal University, Academic Journal: Social Science Edition, 2013, 36(6): 854-858.

[4] Guo Fenyun, Chang Lili. The Loss and Pursuit of College Classroom Teaching [J]. Educational Theory and Practice, 2006 (2): 39-41.

[5] Li Hua, Wu Yunyong. Analysis of "interactive" teaching mode [J]. Journal of Shenyang Normal University: Social Science Edition, 2008, 31(3): 77-79 